\title{
Inovação e precarização do trabalho no Brasil: impactos sobre os profissionais da saúde
}

\section{Innovation and precarialization of work in Brazil: impacts on health professionals}

Enaire de Maria Sousa da Silva ${ }^{1}$, Eduardo Mohana Silva Ferreira ${ }^{2}$, Railson Marques Garcez ${ }^{3}$, André Gustavo Mota Sousa ${ }^{4}$

\begin{abstract}
RESUMO
O contexto neoliberal de desmonte das políticas públicas, especialmente das de saúde, tem ensejado discussões e reflexões acerca do processo de precarização dos trabalhadores dessa área em razão da introdução de novas tecnologias. A implementação de modelos de gestão empresariais que buscam aumentar a produtividade do trabalho e a redução de custos tem promovido uma maior intensificação do trabalho dos profissionais da área de saúde por meio da utilização de Tecnologias de Informação e Comunicação que são consideradas fatores de precarização. Nesse sentido, o presente artigo tem como intuito discutir os principais impactos ocasionados sobre os processos de trabalho de profissionais da saúde mediante a inserção de tecnologias nas instituições de saúde. Trata-se de uma revisão bibliográfica organizada em cinco partes que contempla introdução, três capítulos de discussão teórica, e as considerações finais. O estudo apontou aspectos de precarização de trabalho sobre os profissionais de saúde provocados pela inserção de tecnologia, fator que contribui com o contexto de flexibilização e intensificação do trabalho já instaurado pelas políticas neoliberais que privilegiam os elementos gerenciais como metas, concorrência e valores mercadológicos que remetem ao processo de reordenamento do Estado brasileiro e das investidas de privatização.
\end{abstract}

Palavras-chave: Inovação; Precarização; Trabalho; Saúde.

\begin{abstract}
The neoliberal context of the dismantling of public policies, especially those of health care, has given rise to discussions and reflections about the process of precariousness of workers in this area due to the introduction of new technologies. The implementation of business management models that seek to increase labor productivity and cost reduction has promoted a greater intensification of the work of health professionals through the use of Information and Communication Technologies, which are considered factors of precarization. In this sense, this article aims to discuss the main impacts caused on the work processes of health professionals through the insertion of technologies in health institutions. This is a literature review organized in five parts that includes an introduction, three chapters of theoretical discussion, and the final considerations. The study pointed out aspects of work precarization on health professionals caused by the insertion of technology, a factor that contributes to the context of flexibilization and intensification of work already established by neoliberal policies that emphasize managerial elements such as goals, competition and market values that refer to the process of reordering the Brazilian State and the privatization onslaughts.
\end{abstract}

Keywords: Innovation; Precariousness; Work; Health.

\footnotetext{
${ }^{1}$ UNB. E-mail: sousaenaire@gmail.com

${ }^{2}$ UFMA. E-mail: eduardomohana@ hotmail.com

${ }^{3}$ UFMA. E-mail: railsongarcez.uema@gmail.com

${ }^{4}$ UEMA. E-mail: agmota12@gmail.com
} 


\section{INTRODUÇÃO}

A década de 1990 demarcou mudanças no curso socioeconômico do Brasil. As necessidades de readequação do modelo de desenvolvimento do país aos moldes do capital internacional impactaram em diferentes âmbitos da sociedade e tem acirrado desigualdades sociais que, apesar de históricas, se reconfiguraram através das alterações na relação capital-trabalho.

Em virtude desse contexto, as políticas sociais do Brasil têm sido alvo de desmontes, tendo em vista a estratégia de corte de custos públicos aderida pelo Estado. Tendências referentes à focalização, privatização e seletividade têm caracterizado as medidas de intervenção estatal sobre as expressões da "questão social". Concomitantemente, ganhou ênfase a necessidade da inovação como meio ideal ao progresso dos países, de modo que a disseminação de tecnologias é percebida como ferramenta indispensável ao processo de desenvolvimento e dinamização dos processos de produção.

Os dois contextos têm provocado, desde a segunda metade do século $\mathrm{XX}$, reflexos específicos sobre o conjunto de profissionais de saúde do Brasil. Diante disso, este artigo tem como objetivo discutir os principais impactos provocados pela inovação no âmbito dos trabalhadores da saúde.

Nesse sentido, utilizou-se o recurso teórico-bibliográfico com abordagem qualitativa, a partir de materiais e publicações acadêmicas que abordam e subsidiam este tema de estudo. Dividido em cinco partes, sendo a primeira delas esta introdução, o artigo aborda no segundo capítulo aspectos sobre a inovação e os processos de reestruturação produtiva afim de compreender a importância da inovação na contemporaneidade; no capítulo três, apresenta-se o processo de precarização do trabalho, iniciado a partir da década de 1990, mas que se estende até os dias atuais no Brasil; no quarto capítulo faz a relação do uso de tecnologias nos processos de trabalho na área da saúde; e por fim, no último capítulo são apresentadas as principais conclusões deste estudo.

\section{INOVAÇÃO E A REESTRUTURAÇÃO DOS PROCESSOS PRODUTIVOS}

Para entender como a inovação atua no estabelecimento no capitalismo, torna-se necessário compreender, preliminarmente, os reflexos da emergência do Neoliberalismo. 
O surgimento das ideias neoliberais se deu logo após a II Guerra Mundial na Alemanha Ocidental, influenciado pelas bases teóricas da obra de Friedrich Hayek, "O caminho da servidão”, de 1944 (CERQUEIRA, 2008).

John Clarke argumenta que "o neoliberalismo surgiu com caráter de onipotência, como uma alegada causa primeira - e última - de uma série de desenvolvimentos contemporâneos, ele substituiria a análise específica e cuidadosa de relações de dominação, exploração e alienação" (CLARKE, 2008, p.32).

De acordo com Perry Anderson, a chegada da grande crise do modelo econômico do pós-guerra, em 1973, fez com que "toda a economia capitalista avançada caísse numa longa e profunda recessão, combinando, pela primeira vez, baixas taxas de crescimento com altas taxas de inflação" (ANDERSON, 1995, p.10). A partir de então, as ideias neoliberais passaram a ser disseminadas, e o Estado de Bem-Estar deu lugar à busca pelo crescimento econômico sustentado em preceitos do livre mercado, e a consequente abertura comercial.

Nos anos de 1960 o capitalismo se deparou com a crise das economias do capitalismo central devido aos substanciais recessos econômicos. Nesse cenário, as grandes e médias empresas operavam abaixo de sua capacidade de produção e, com isso, houve uma redução das taxas, seguida de um aumento na inflação. As políticas neoliberais, então, encontraram um ambiente propício para a expansão de seus preceitos na Inglaterra e nos Estados Unidos, com as eleições de Margareth Thatcher (1979) e Ronald Reagan (1980).

Entre as ideias neoliberais, destaca-se o enfraquecimento de movimentos sindicais organizados e a busca pelo equilíbrio do balanço de pagamentos, assim como a redução da participação do Estado na economia e no processo de produção industrial. Com a emergência neoliberal, o Estado deveria, apenas, tornar viáveis as reformas fiscais como forma de incentivar a autonomia dos agentes econômicos. O Estado neoliberal também implementou medidas que acirraram as desigualdades sociais, que atingiram diretamente as classes mais desfavorecidas. Em meio às principais tendências destaca-se a redução constante e progressiva dos gastos públicos em setores como saúde e educação, dessa forma, uma noção oposta ao que fora executado no Estado de Bem-Estar.

Com a ascensão do neoliberalismo, as desigualdades socioeconômicas foram acirradas em nível global, inclusive nos países desenvolvidos, com a elevação do desemprego estrutural e a consequente redução do poder de compra dos sujeitos. $\mathrm{O}$ 
arrocho salarial, ademais, desencadeou em mazelas provenientes da desigualdade social, como a pobreza extrema e a fome (GUIDO, 1999).

O contexto de desmonte, em conjunto com a efervescência em torno da inovação refletiram significativamente sobre o contexto do trabalho. De acordo com Dean Morse e Aaron W. Warner (1966), até o século XVIII o agente inovador era considerado uma pessoa suspeita, sem credibilidade. Somente a partir do século $\mathrm{XX}$ foi que se deu importância à inovação, sobretudo enquanto fator promotor de crescimento econômico.

Schumpeter conceitua a inovação como "a introdução comercial de um novo produto ou uma nova combinação de algo já existente, criado a partir de uma invenção que, por sua vez, pertence ao campo da ciência e tecnologia" (SCHUMPETER, 1997, p 46). De acordo com Morse e Warner, "não existe inovação pura e simples, porque muitas são as maneiras pelas quais se pode inovar. Existem muitas indústrias e problemas e cada um deles é bastante diferente" (MORSE; WARNER, 1966, p.15).

O início do século XX é marcado pelo estudo da íntima relação existente entre a inovação e a tecnologia. Esse elo representava, para os agentes econômicos da época, a gênese do processo de crescimento da economia. Carol Proner (2007) argumenta que:

O início do século XX destaca-se como um período dominado pela fé cega no progresso econômico em que tudo que pudesse ser transformado em fonte de riqueza e objeto de desejo da nova classe consumidora passa a receber atenção especial. Pesquisadores afirmam que a inovação tecnológica (IT), objeto de proteção da propriedade intelectual industrial, representaria o motor da atividade econômica do novo século, exercitando novas técnicas de estímulo e de acesso a invenções por meio de investigações científicas. (PRONER, 2007, p.30).

A inovação dispõe de mecanismos para reduzir custos e aumentar a produtividade, são eles as mudanças de tecnicidades que correspondem à realocação das técnicas industriais na produção de mercadorias e serviços. Nesse processo o trabalhador sofre inúmeras consequências degradantes como, por exemplo, a substituição da força de trabalho por maquinarias capazes de realizar seu laboro por menor custo e em menor duração de tempo.

A inserção técnica acarretou em uma nova configuração de desenvolvimento capitalista, onde a produção de mais-valia (MARX, 2017) - expressão exata do grau de exploração da força de trabalho pelo capital ou do operário pelo capitalista - não foi centrada no incremento da força produtiva do trabalho, mas sim em mecanismos que 
tinham em comum o fato de que implicavam o desvio do preço da força de trabalho em relação ao seu valor, fenômeno denominado por Marini (1972) de "superexploração".

Com as transformações causadas pelas mudanças nas técnicas produtivas, a exploração do trabalho se intensificou, tornando-se uma realidade cada vez mais degradante neste último século. Diante de tal contexto, é possível mencionar uma consequência direta acarretada pela defesa à inovação: o trabalho informal. Para esse autor, "a exaltação às condições precárias do trabalhador informal, consiste em sintomática confissão de fracasso do neoliberalismo e de sua flexibilização trabalhista, um sistema destruidor de empregos" (KATZ, 2016, p. 102).

As consequências oriundas das mudanças nas técnicas de produção, tendo como base a inovação, não vêm sendo assistidas pelo Estado, tendo em vista a necessidade de minimizar tais impactos sobre a sociedade. Pelo contrário, o que tem sido observado, sobretudo no século corrente, são governos defensores do crescimento econômico a qualquer custo, sustentados em medidas que retiram direitos e desmontam os sistemas de proteção social nacionais.

Desse modo, compreende-se que o advento da inovação em conformidade com o contexto neoliberal dos Estados-nacionais, predominante desde a segunda metade do século XX, têm favorecido a substituição do trabalhador por tecnologias de ponta, de modo que, o que a priori poderia se tratar de um processo restrito às indústrias e empresas, passa a compor também o universo dos espaços públicos, a partir da precarização das políticas sociais públicas.

No Brasil, ganha destaque o contexto do Sistema Único de Saúde (SUS), que tem se tornado espaço de precarização do trabalho em virtude, dentre outros aspectos, da inserção de processos de trabalho mais inovadores, com a disposição de novas tecnologias, mas, que, no cotidiano, têm representado ataques à humanização de atendimentos, redução na contratação de profissionais da saúde e precarização das funções daqueles que se encontram em atuação.

\section{A PRECARIZAÇÃo do trabalHo A PARTIR dA DÉCAdA de 1990 NO} BRASIL

O trabalho, enquanto a categoria fundante do ser social, sempre esteve em uma posição central perante à sociedade, uma vez que se situa enquanto interação entre homem 
e natureza e também se mostra indispensável para a reprodução do ser humano e para o desenvolvimento da sociedade como um todo (MARX, 2017; LUKÁCS, 2013). Em outras palavras, compreende-se que, devido ao trabalho, o ser humano pode desenvolver ao longo da evolução humana a capacidade de se constituir em sociedade e se relacionar com os demais. Nesse sentido, o trabalho adquire prioridade ontológica na análise da constituição do ser social.

Foi a partir do surgimento do sistema capitalista, e da necessidade de obtenção de lucro por parte de uma classe dominante, que a força de trabalho passou a ser alvo de mercantilização, a fim de que a dinâmica do sistema pudesse ser mantida. Nesse sentido, a principal peculiaridade adquirida pela força de trabalho mediante a inserção capitalista é a sua mercantilização, de modo que a sua compra e venda é o que promoverá a exploração da burguesia sobre a classe trabalhadora. O trabalho subsidiado pelas vontades de outrem o qualifica como alienado, tendo em vista o não reconhecimento do trabalhador sobre os processos operados. Esta condição só é possível devido à mercantilização da força de trabalho e, portanto, é específica de uma sociedade capitalista (MARX, 2017).

Apesar destes aspectos que compõem a configuração geral do trabalho dentro do capitalismo, essa categoria foi alvo de alterações na medida em que o sistema se modificou: as necessidades de diminuição de custo na produção, com a crescente demanda pelo aumento dos lucros, fizeram com que os processos de trabalho fossem alterados para satisfazer os grandes capitalistas. As inovações técnico-científicas trazem consigo a necessidade de novos processos de trabalho e, consequentemente, de mudanças no padrão de uso da força de trabalho no processo produtivo. A adoção do regime de acumulação flexível, associado à implementação das políticas neoliberais, faz com que o trabalho seja um dos principais alvos de alteração, justamente por este ser o elemento de fomento à reestruturação produtiva. A atual configuração da classe trabalhadora, compreende

(...) a totalidade dos assalariados, homens e mulheres que vivem da venda de sua força de trabalho em troca de salário, seja na indústria, na agricultura e nos serviços, seja nas interconexões existentes entre esses setores, como na agroindústria, nos serviços industriais, na indústria de serviços etc. Dadas as profundas metamorfoses ocorridas no mundo produtivo do capitalismo contemporâneo, o conceito ampliado de classe trabalhadora, em sua nova morfologia, deve incorporar a totalidade dos trabalhadores e trabalhadoras, cada vez mais integrados pelas cadeias produtivas globais e que vendem sua força de trabalho como mercadoria em troca de salário, sendo pagos por capital-dinheiro, não importando se as atividades que realizam sejam predominantemente 
materiais ou imateriais, mais ou menos regulamentadas (ANTUNES, 2018, p. 36).

Dessa forma, as transformações das quais o trabalho foi alvo desde o fim do século XX, não anularam sua centralidade no capitalismo, e tampouco ocasionaram o fim da classe trabalhadora. As mudanças nos processos de produção não poderiam ter sido viáveis sem a reconfiguração do trabalho e, consequentemente, da classe trabalhadora, que agora ocupa novas posições e se depara com novos desafios frente aos fatores de precarização que se colocam. Com base nisso, o que tem se apresentado à sociedade é uma nova Divisão Internacional do Trabalho, decorrente dos processos de reestruturação capitalista (ANTUNES, 2018).

No geral, a adoção dos métodos flexíveis surge nos contextos nacionais justificada pela necessidade de redução do desemprego. Nesse sentido, os Estados buscam facilitar a redução dos custos de contratação e direitos trabalhistas, a fim de que os empresários sejam impulsionados a contratar mais trabalhadores, considerando que eles deixariam de ser tão onerosos. No entanto, o que se tem observado é que a redução dos custos de contratação tem precarizado as condições de trabalho dos indivíduos, ao tempo em que o lucro dos grandes empresários é potencializado e a questão do desemprego sequer é amenizada (KREIN, 2004).

A necessidade de redução nos custos com mão-de-obra, e posterior potencialização dos lucros, faz com que se requisite o menor quantitativo possível de trabalhadores que, para assegurar suas ocupações, devem ser multifuncionais. Trata-se de uma realidade oposta ao que ocorria no auge do regime fordista dentro dos países do capitalismo central, no qual se buscavam trabalhadores especializados e, dessa forma, havia a necessidade da contratação de inúmeros indivíduos que pudessem preencher todas as etapas da produção. Consequentemente, foi possível viabilizar a política de pleno emprego, garantindo a compatibilização entre os padrões de produção e de consumo de massa.

Krein (2001) analisa que desde a década de 1990, os focos dos processos de precarização têm estado, sobretudo, sobre as relações de emprego, e envolve aspectos relacionados às formas de contratação do trabalho, ao tempo de trabalho, e às mudanças no padrão de remuneração. O espaço público, que tem se tornado alvo das investidas a partir da Reforma Gerencial do Estado, já apresenta todas as tendências analisadas acima, e se caracteriza como o novo espaço de inserção dos aspectos de precarização inerentes ao capitalismo contemporâneo. 
No âmbito do trabalho em saúde, as condições de trabalho são duplamente afetadas pois, além do contexto de flexibilização intrínseco ao atual estágio do capital, tem-se o desmonte de políticas sociais, característico das interventivas neoliberais, e que também irão justificar o subfinanciamento na saúde pública do país (BEHRING; BOSCHETTI, 2009). Considerando o avanço da inovação nos processos de trabalho, inclusive no âmbito das políticas sociais, torna-se necessário compreender as principais discussões acerca da entrada de novas tecnológicas no cenário de saúde brasileiro.

\section{O TRABALHO EM SAÚDE E AS NOVAS TECNOLOGIAS}

Analisar o trabalho em saúde pressupõe reconhecer algumas particularidades, sobretudo no que tange ao excesso de demandas e atendimentos, além da frequente convivência com contextos reconhecidos, socialmente, como complexos e de intensa sobrecarga emocional sobre os trabalhadores, a exemplo das situações de óbitos, contatos frequentes com a rede sociofamiliar de pacientes e, em um contexto de subfinanciamento das políticas sociais, com a constante ausência de insumos e materiais de trabalho.

Diante deste universo, tendo em vista os recentes reflexos da reestruturação produtiva, torna-se de grande utilidade conceituar, brevemente, a correlação dos modelos de serviços de saúde prestados em momentos anteriores ao incentivo da inovação, assim como o que tem predominado no capitalismo contemporâneo.

Ao analisar a prática médica, Schraiber (1995) destaca o modelo médico liberal, e o modelo médico tecnológico. Segundo a autora, o primeiro modelo esteve em vigor até a década de 1960, e é caracterizado por uma abordagem clínica, com profissionais médicos atuando em ambiente privado, a exemplo dos consultórios, enquanto o modelo tecnológico corresponde ao atual modo de intervenção, caracterizado pelo alto teor de especialização, e intenso suporte de aparelhos instrumentais.

Peduzzi (2002), suscita a discussão do trabalho em saúde na contemporaneidade ao apontar que:

Dadas as características de setor terciário e as peculiaridades do objeto de trabalho - as necessidades de saúde, sentidas e trazidas aos serviços pelos sujeitos/usuários e apreendidas e interpretadas tecnicamente pelos sujeitos/ agentes do trabalho - o trabalho em saúde configura-se como trabalho reflexivo, destinado à prevenção, manutenção ou restauração de "algo" (a saúde) imprescindível ao conjunto da sociedade. Chama a atenção a proximidade de algumas características do trabalho em saúde e das mudanças referidas ao novo modo de operar o trabalho na 
sociedade contemporânea. A nosso ver, tais semelhanças dão-se pela configuração do primeiro como trabalho reflexivo, e pela atual tendência à maior intelectualização do trabalho em geral, sobretudo pela incorporação da microeletrônica e da informática. Salientamos, portanto, a natureza peculiar do trabalho em saúde e a forma particular como desenvolveram-se os estudos nesse campo, atribuindo relevância à dimensão do saber. (PEDUZZI, 2002, p. 93).

Tendo em vista a inserção do neoliberalismo nos Estados-nacionais, assim como a necessidade da adoção de reformas para que as ideias de livre comércio e flexibilização da força de trabalho fossem implementadas nos países, o contexto requer situar a Reforma Gerencial do Estado brasileiro ${ }^{5}$, implementada no país na década de 1990, e responsável por regulamentar novos padrões de gestão sobre as políticas públicas, incluindo nestas a saúde.

A inserção dos ditames gerenciais no âmbito da saúde brasileira provocou, dentre outros aspectos, a implementação de modelos de gestão empresariais, focados no aumento da produtividade, e na redução de custos com mão-de-obra. Mediante tais necessidades, o incremento de inovação tecnológica em instituições de saúde surge vinculado à necessidade de dinamização dos atendimentos e melhoria dos serviços prestados, apesar disso, tem exigido dos profissionais de saúde o manejo de máquinas auxiliares, ao tempo em que ainda devem desempenhar as funções tipicamente assistenciais, anteriormente já estabelecidas. (PEDUZZI, 2002).

A introdução de elementos gerenciais na saúde púbica do Brasil tem favorecido para que seja levado às instituições valores mercadológicos, com a inserção de sistemas de metas, reverência à concorrência, e estímulo a um potencial mercado consumidor. (PACHECO et. al., 2005). Tal contexto é resultado das investidas de privatização oriundas do reordenamento do Estado brasileiro que, desde a década de 1990 estimula e financia novas estratégias de desresponsabilização estatal, a exemplo das Organizações Sociais (OS) e Organizações da Sociedade Civil de Interesse Público (OSCIP).

\footnotetext{
${ }^{5}$ Em 1995, com Luís Carlos Bresser-Pereira a frente do Ministério da Administração Federal e Reforma do Estado do governo FHC, deu-se início à Reforma Gerencial do Estado com vistas a melhorar a eficiência na gestão do setor público do país. Com base nisso, lançou-se o Plano Diretor da Reforma do Aparelho do Estado (1995) com vistas à reestruturação do modelo de administração pública, sustentada em reajustes fiscais, nas linhas de intervenção do Estado e adesão de critérios empresariais no processo de gestão.
} 
Pires et. al. (2012) apresentaram resultados referentes às Tecnologias de Informação e Comunicação (TIC). Segundo o estudo, a introdução de inovações tecnológicas nos processos de trabalho assistenciais possui três fases de resultados:

Primeiro, na fase inicial ocorre aumento das cargas de trabalho, pois os trabalhadores precisam ser capacitados para o manuseio dos novos instrumentos de trabalho ou para trabalhar de outra maneira [...]. Segundo, quando a implantação das TIC implicou em afastamento entre profissional e paciente houve certa resistência à inovação, assim como insatisfação e aumento das cargas de trabalho, especialmente dos profissionais de enfermagem. Em terceiro lugar, os estudos mostraram que quando o/a trabalhador/a é incluído em todas as fases do processo, do planejamento à avaliação, os efeitos negativos são minimizados e os reflexos sobre as cargas de trabalho diminuem. Cinco grandes questões devem ser abordadas para promover a implementação bem sucedida dos registros de saúde eletrônicos: financiamento e disponibilidade de equipamentos; interoperabilidade; padronização e conectividade dos sistemas de informação clínica; redesenho do fluxo de trabalho, apoio técnico e formação; e gestão da mudança (PIRES et. al., 2012, p. 163).

A grande questão é que, para que a terceira etapa de resultados seja alcançada, e tais efeitos sejam minimizados, seriam necessários, conforme apontado na citação, elementos que só podem ser proporcionados por um Estado comprometido com a implementação de uma saúde pública conforme prevê as legislações, longe disso, o Estado neoliberal tem priorizado investimentos na iniciativa privada do país, tornando o fundo público objeto de disputa entre os empresários nacionais e grandes instituições financeiras. (SALVADOR, 2010).

Menezes, Moretti e Reis (2019, p. 67) afirmam que "os impactos sobre o SUS se dão em um contexto que combina desfinanciamento da saúde e medidas que materializam no sistema posições de valor estranhas a seus pressupostos constitucionais", desse modo, há um contexto que propicia que os trabalhadores da saúde estanquem nas duas primeiras fases mencionadas no estudo de PIRES et. al. (2012), configurando, dessa forma, a inserção de TIC como um fator de precarização ao trabalho de tais sujeitos.

A priori, pode parecer inconcebível que inovações tecnológicas carreguem consigo contextos de precarização, uma vez que, no século da "globalização"6 e do

\footnotetext{
${ }^{6}$ Corriqueiramente, o termo tem sido utilizado de modo a definir uma era global, em que o consumo e os costumes passam a ser definidos de modo padrão e o mundo todo passa a desfrutar das vantagens proporcionadas pela produção capitalista. No entanto, o fim do século passado, marcado pelo início de utilização do termo e, sobretudo, pelas mudanças macroeconômicas sustentadas na acumulação flexível,
} 
desenvolvimento tecnológico de ponta, há uma defesa ideológica de tudo aquilo que, conforme discutido na primeira seção, represente progresso para a humanidade. Da mesma forma, no âmbito da saúde, faz-se necessário mencionar que as mudanças são não apenas estruturais, ademais:

a tecnologia não é apenas um fator de produção e organização do trabalho. Ao mesmo tempo, é também, um elemento estruturador de modelos de atenção e práticas de saúde. Por isso, é um fator ideológico, colaborando para a construção de novos padrões de consumo e procura de cuidados, repercutindo coletivamente na população. (CHIAVEGATO FILHO; NAVARRO, 2012, p. 78).

Em um contexto de baixa empregabilidade, além dos conhecimentos profissionais básicos, aos profissionais de saúde tem sido exigido o domínio de ferramentas tecnológicas como condição de desenvolvimento de seus processos de trabalho. O estudo de Pacheco et. al. (2005) concluiu a predominância de efeitos negativos sobre os profissionais de saúde, tendo em vista as atuais exigências cognitivas impostas sobre os mesmos, de modo que "é de se esperar que o distress seja um fenômeno cada vez mais comum entre os trabalhadores, o que pode ser constatado pelos casos de desequilíbrios psicossomáticos e doenças ocupacionais evidentes e/ou emergentes". (PACHECO, et al., 2005, p. 119).

O contexto pandêmico trouxe ao cenário do trabalho em saúde novos aspectos de precarização vinculados, inclusive, às tendências de inovação. Segundo a Associação Brasileira de Planos de Saúde (Abramge), foram realizadas mais de 2,5 milhões de teleconsultas entre abril de 2020 e março de 2021. Acerca da temática, o médico Marcos Alvarez escreveu ao portal "SaúdeOcupacional.org":

[...] existe a implantação de modelos de atendimento à saúde que maximizam os lucros, como a imposição do conceito de produtividade industrial ao atendimento médico pelas grandes corporações, sem considerar a qualidade. Nestes casos, o pagamento de um pequeno valor por peça produzida (consulta, por exemplo) obriga o trabalhador (médico) a realizar número excessivo de atendimentos. A responsabilidade pela qualidade do atendimento, entretanto, continua sendo do médico (ALVAREZ, 2021, online).

demonstra que as desigualdades estruturais foram agravadas e que a maior parte da população mundial não dispunha de condições mínimas à reprodução social. (IANNI, 1994). 
A fala do profissional permite compreender que o atual contexto - demarcado pela inserção de tecnologias que evitam o contato presencial e ainda assim possibilitam a realização dos processos de trabalho - tem contribuído para a inserção de preceitos mercadológicos no âmbito da saúde, com o investimento em mecanismos de redução de custos de mão-de-obra, ao tempo em que os atendimentos são potencializados.

Certamente, essa discussão não desconsidera a necessidade de que os profissionais de saúde tenham condições de se prevenir do contágio pelo novo coronavírus, longe disso, compreende-se que o atual contexto sanitário não deve ser utilizado como ferramenta propícia à intensificação de fatores de precarização que já existiam e que, apesar da situação do país, têm sido justificados pela necessidade de ampliação dos lucros por parte de grupos específicos.

\section{CONSIDERAÇÕES FINAIS}

O desmonte de políticas públicas em um contexto neoliberal é multifatorial, este trabalho buscou demonstrar os principais elementos que justificam a precarização através de um fator específico fomentado nos últimos anos, a inovação. Dessa forma, foi demonstrado que a inserção dos preceitos inovadores no âmbito das políticas públicas, em especial no caso da saúde, deve ser contextualizada com a atual fase do capital, de modo a identificar processos de continuidade e correlação com o padrão apresentado na categoria trabalho.

Em um contexto neoliberal, foi possível compreender de que forma a saúde passa a se configurar como ambiente para a inserção de inovação e, sobretudo, espaço para a precarização das condições de trabalho. Os reflexos apontados confirmam que o debate em torno da inovação, para além do discurso do progresso, também deve considerar o desenvolvimento dos processos de trabalho, sobretudo, no âmbito da Política Pública de Saúde.

\section{REFERÊNCIAS}

ANDERSON, Perry. Balanço do Neoliberalismo. In: EMIR, Sader; gentili, Pablo Gentil (ORG.). Pós-neoliberalismo: As Políticas Sociais e o Estado Democrático. 4. Ed. Rio de Janeiro: Paz e Terra, 1995.

ANTUNES, R. O Privilégio da Servidão. $1^{\text {a }}$ ed. São Paulo: Boitempo, 2018. 
ASSOCIAÇÃO BRASILEIRA DE PLANOS DE SAÚDE (Abrange). A sociedade e a precarização da medicina. 2021. Disponível em: https://abramge.com.br/portal/index.php/pt-BR/. Acesso em: 26.08.2021.

BEHRING, E.; BOSCHETTI, I. Política Social: Fundamentos e história. 6 ed. São Paulo: Cortez, 2009.

CERQUEIRA, J. Uma visão do neoliberalismo: surgimento, atuação e perspectivas. Feira de Santana: UEFS, 2008.

CHIAVEGATO FILHO, Luiz Gonzaga; NAVARRO, Vera Lúcia. A organizacão do trabalho em saúde em um contexto de precarização e do avanço da ideologia gerencialista. Revista Pegada, São Paulo, vol. 13, n.2, 2012.

CLARKE, J. Living With/in and Without Neoliberalism. Focaal, v. 51, n. 1, p. 135147, 2008.

GUIDO, José. Diaconia e Modernidade. São Paulo: Gráfica e Editora A Voz do Cenáculo, 1999.

KATZ, Claudio. Neoliberalismo, Neodesenvolvimentismo, Socialismo. Tradução Maria Almeida. 1a ed. São Paulo: Expressão Popular: Perseu Abramo, 2016.

KREIN, José Dari. A reforma trabalhista de FHC: análise de sua efetividade. Revista do Tribunal Regional do Trabalho da 15ª Região, Campinas, n. 24, p. 270-299, 2004.

O aprofundamento da flexibilização das relações de trabalho no Brasil nos anos 90. 2001. 202 f. Dissertação (Mestrado em Economia Social e do Trabalho) Instituto de Economia, Universidade Estadual de Campinas, Campinas/SP, 2001.

LUKÁCS, G. Para uma ontologia do ser social II. São Paulo: Boitempo, 2013.

MARINI, Ruy Mauro. Dialéctica de la dependência. México: Era, 1972.

MARX, K. O Capital: Crítica da Economia Política. São Paulo: Boitempo, 2017.

MENEZES, Ana Paula do Rego; MORETTI, Bruno; REIS, Ademar Arthur Chioro dos. O futuro do SUS: impactos das reformas neoliberais na saúde pública austeridade versus universalidade. Saúde em debate, Rio de Janeiro, 43 (spe5) 19 Jun 2020/Dez 2019.

MORSE, Dean; WARNER, Aaron W. A Inovação Tecnológica e a Sociedade. Rio de Janeiro: Freiras Bastos, 1966.

PACHECO et al. A era da tecnologia da informação e comunicação e a saúde do trabalhador. Rev. Bras. Med. Trab., Belo Horizonte, vol. 3, no 2, p. 114-22, ago-dez 2005.

PEDUZZI, Marina. Mudanças tecnológicas e seu impacto no processo de trabalho em Saúde. Trabalho, Educação e Saúde, Rio de Janeiro, 1(1):75-91, 2002.

PIRES et al. Inovação tecnológica e cargas de trabalho dos profissionais de saúde: uma relação ambígua. Rev. Gaúcha Enferm, Rio Grande do Sul, 33 (1), mar 2012. 
PRONER, Carol. Propriedade Intelectual: Para uma outra ordem jurídica possível. São Paulo: Cortez Editora, 2007.

SALVADOR, Evilasio da Silva. Fundo público e políticas sociais na crise do capitalismo. Serviço Social \& Sociedade, São Paulo, n. 104, p. 605-631, out./dez. 2010.

SCHRAIBER, L B. Work in Medicine: Some Questions About the Professional Autonomy. Cad. Saúde Públ., Rio de Janeiro, 11 (1): 57-64, Jan/Mar, 1995.

SCHUMPETER, Joseph. The instability of capitalism. Connecticut. Ed. Economic Journal, 1928. Teoria do desenvolvimento econômico: uma investigação sobre lucros, capital, crédito, juro e o ciclo econômico (1 ed., 1934). Tradução de Maria Sílvia Possas. Coleção Os Economistas. São Paulo: Nova Cultural, 1997.

Recebido em: 01/10/2021

Aprovado em: 05/11/2021

Publicado em: 10/11/2021 